\title{
Serum Calprotectin (S100A8/A9): A Promising Biomarker in Diagnosis and Follow-up in Different Subgroups of Juvenile Idiopathic Arthritis
}

Céline La ( $\nabla$ celine.la@ulb.be )

CHU Brugmann - Site Victor Horta: UVC Brugmann - Site Victor Horta https://orcid.org/0000-00026065-2970

Phu Quoc Lê

Reine Fabiola Children's University Hospital: Hopital Universitaire des Enfants Reine Fabiola

\section{Alina Ferster}

Reine Fabiola Children's University Hospital: Hopital Universitaire des Enfants Reine Fabiola

\section{Laurence Goffin}

Reine Fabiola Children's University Hospital: Hopital Universitaire des Enfants Reine Fabiola

\section{Delphine Spruyt}

Universite Libre de Bruxelles

\section{Bernard Lauwerys}

Cliniques Universitaires Saint-Luc

\section{Patrick Durez}

Cliniques Universitaires Saint-Luc

\section{Cecile Boulanger}

Cliniques Universitaires Saint-Luc

\section{Tatiana Sokolova}

Cliniques Universitaires Saint-Luc

Joanne Rasschaert

Université Libre de Bruxelles: Universite Libre de Bruxelles

\section{Valérie Badot}

CHU Brugmann - Site Victor Horta: UVC Brugmann - Site Victor Horta

\section{Research article}

Keywords: Juvenile idiopathic arthritis, Inflammation, Outcome Assessment, Health Care

Posted Date: May 10th, 2021

DOI: https://doi.org/10.21203/rs.3.rs-138436/v2 
License: (c) (i) This work is licensed under a Creative Commons Attribution 4.0 International License. Read Full License 


\section{Abstract}

\section{Introduction}

In the management of juvenile idiopathic arthritis (JIA), there is a lack of diagnostic and prognostic biomarkers. This study assesses the use of serum calprotectin (sCal) as a marker to monitor disease activity, and as a classification and prognosis tool of response to treatment or risk of flares in patients with JIA.

\section{Methods}

Eighty-one patients with JIA from the CAP48 multicentric cohort were included in this study, as well as 11 non-pediatric healthy controls. An enzyme-linked immunosorbent assay (ELISA) method was used to quantify sCal with a commercial kit.

\section{Results}

Patients with an active disease compared to healthy controls and to patients with inactive disease showed an 8-fold and a 2-fold increased level of sCal respectively. sCal was found to be correlated with the CRP and even more strongly with the ESR. Evolution of DAS28 scores correlated well with evolution of sCal, as opposed to evolution of CRP. With regard to CRP, sCal could differentiate forms with active oligoarthritis from polyarthritis and systemic forms. However, sCal brought an added value compared to the CRP as a prognosis marker. Indeed, patients with active disease and reaching minimal disease activity (according to JADAS) at 6 months following the test had higher sCal levels, while patients with inactive disease had higher sCal levels if a flare was observed up to 3 to 9 months following the test.

\section{Conclusions}

This study confirms the potential uses of serum calprotectin as a biomarker in the diagnosis and followup of JIA.

\section{Introduction}

Juvenile idiopathic arthritis (JIA) represents a very heterogeneous disease and is divided in 7 sub-groups according to the International League of Associations for Rheumatology (ILAR) classification: oligoarthritis, rheumatoid factor (RF)-positive and -negative polyarthritis, enthesitis-related arthritis, psoriatic arthritis, systemic arthritis and undifferentiated arthritis.[1] JIA can be associated with significant morbidity and mortality and represents an important cause of short-term, and long-term, disability.[2,3]

Immune pathogenesis of JIA is still incompletely understood. Disease probably results, as with most autoimmune diseases, from a combination of genetic susceptibility (HLA and non HLA-related genes), environmental factors, and over-activation of innate and adaptive (T-cell or B-cell) immunity.[3] 
The course of the disease is characterized by alternating periods of flares and remission. Some predictors of poor outcome have been identified (presence of RF, early radiographic changes, symmetrical disease, extension of arthritis at onset, positivity of antinuclear antibodies [ANA]), but a lack of precise and reliable prognosis factors remains a major problem in JIA.[2,3]

Serum calprotectin (sCal), also known as myeloid-related protein (MRP) 8/14, is part of the $\mathrm{S} 100$ proteins family (with pro-inflammatory effects) and is formed by a stable heterodimer of S100A8 and S100A9 subunits. [4] It has been described in many studies involving numerous inflammatory diseases (Crohn's disease, cystic fibrosis, sepsis, etc.),[5-7] including rheumatologic diseases (rheumatoid arthritis, systemic lupus erythematosus, etc.),[8-12] and, more recently, in severe forms of COVID-19.[13]

In JIA, sCal was shown to be elevated in patients with active disease, particularly in the systemic form, helping to distinguish them from patients with infections or malignant disease (which can present as a hard differential diagnosis at first).[14-16] sCal has also shown promising results as a biomarker by predicting disease relapse after stopping NSAIDs,[17] methotrexate[18,19] or etanercept[20] treatment.

In this study, we intended to measure sCal in a Belgian population of JIA patients among the CAP48 cohort and to correlate its level with the different clinical subgroups of JIA, disease activity and outcome (to evaluate the response to treatment in patients with active disease or the risk of flares in inactive disease).

\section{Methods}

\section{Study design}

The patients were enrolled from an observational multicentric study (CAP48 cohort) and followed for a duration of 2 years at the time of this study (from January 2014 to January 2016). Patients were included from 5 different hospitals in Brussels and Wallonia (including Hôpital Universitaire des Enfants Reine Fabiola, Cliniques Universitaires Saint-Luc, Hôpital Erasme, Cliniques Universitaires Mont-Godinne and Clinique Saint-Pierre Ottignies).

The CAP48 cohort is divided in 2 subgroups: patients naïve to any DMARD therapy at the time of inclusion (intraarticular corticosteroids were allowed) and patients with an established disease (already treated with a DMARD). The patients were followed every 3 months during first year of follow-up, and subsequently every 6 months. Details of this study are described elsewhere.

Eighty-one patients were included and classified according to their JIA category and disease activity. Forty-five patients were in a state of disease inactivity or remission (all with an established disease). Thirty-six patients had an active disease at baseline (of whom 35 started a new treatment at baseline), and include 16 naïve and 20 patients with established JIA.

It was decided not to rely on healthy pediatric controls, given the ethical and technical difficulties underlying this type of sampling. Healthy controls were thus young adults and included from the biobank 
of the Department of Rheumatology of Hôpital Erasme.

\section{Definitions}

The inclusion criterion was a diagnosis of JIA according to the ILAR criteria.[1]

At the time of the creation of the CAP48 cohort, the JADAS score was still recent and validated cut-off values had yet to be determined, so disease activity was followed by both DAS28-CRP and JADAS10-CRP scores.[21-25] Disease was thus herein considered active with a DAS28-CRP $\geq 3.2$ or a JADAS10-CRP $>2$ for the oligoarticular and $>3.8$ for the polyarticular forms. The disease inactivity was defined according to the American College of Rheumatology (ACR) criteria revised in 2011,[26] while remission was defined as a persistent inactivity for 6 months under stable treatment.

Response to treatment was assessed by the patients' ability to reach minimal disease activity state at 6 months, according to JADAS cutoffs.[27] The cutoffs for classification of minimal disease activity are defined as 2 for oligoarticular forms of JIA and 3.8 for polyarticular forms of JIA.[27] Finally, the definition of flare was based on the criteria developed in 2002, and characterized by worsening of 2 core outcome variables (COV) by $\geq 40 \%$ without concomitant improvement of more than one of the remaining COV by $\geq 30 \%$.[28] The core set of outcome variables consists of the number of joints with active arthritis, the number of joints with limited range of motion, the physician's global assessment of disease severity on a 10-cm Visual Analogue Scale [VAS], the parent's or patient's global assessment of overall wellbeing on a 10-cm VAS, one laboratory marker of inflammation (erythrocyte sedimentation rate [ESR] or CRP), and a functional assessment tool based on the Childhood Health Assessment Questionnaire (CHAQ). $[28,29]$

\section{Serum calprotectin measurements}

Serum calprotectin was measured at baseline in all 81 patients (with an active or inactive disease). The serum samples were frozen and stored at $-80^{\circ} \mathrm{C}$.

The levels of sCal were measured by ELISA method with a commercial kit (Bühlmann Laboratories AG, Schönenbuch, Switzerland), chosen after a review of literature, that would theoretically deliver more consistent results. The intra-assay coefficient of variability was $5 \%$.

\section{Statistical analysis}

The statistical analyses were made using SPSS v23.0 (IBM®, Armonk, New York, USA) and GraphPad Prism 6 (GraphPad Software Inc., La Jolla, CA, USA).

Categorical data are described as numbers (and in percentages), while continuous data are described according to their mean (and standard error of the mean, or SEM) or their median (and range).

Comparisons were done with non-parametric Mann-Whitney tests. Correlations between measures were assessed with Spearman's rank correlation coefficient. Receiver operating characteristic (ROC) curves 
were also generated to appraise sensitivity and specificity of measuring serum calprotectin as a prognostic tool.

\section{Ethics}

This study complies with the Declaration of Helsinki and the involved Institutional Review Board (IRB) names and approval numbers are as following: Commission d'Ethique Biomédicale Hospitalo-Facultaire de I'UCL (P1200_14) and Comité d'Ethique Erasme-ULB (PE2013_211 for the CAP48 cohort; PE2012_251 for the biobank of the Department of Rheumatology). Informed consent was obtained from each patient and their parents.

\section{Results}

\section{Demographic data at baseline}

The patients had a median age of 12.6 years, with a predominance of female (F:M sex ratio of 1.9:1). The median disease durations were 0.8 and 3.9 years in the naïve and established cohort respectively. Most of patients were treated with MTX and approximately one-fifth of patients were treated with a biologic DMARD. More detailed information about their baseline parameters is available in an additional table file [see Additional file 1]. Patients with active or inactive disease did not differ in age, gender, or JIA subtypes.

The control population had a median age of 26.2 years, with a predominance of female (F:M sex ratio of $1.7: 1)$.

\section{Levels of serum calprotectin according to disease activity and clinical and biological parameters}

The levels of sCal were significantly higher in patients with an active disease than in patients with an inactive disease, illustrated by a 2-fold increased level of sCal $(11403 \mathrm{ng} / \mathrm{mL}$ compared to $6555 \mathrm{ng} / \mathrm{mL})$ (Fig. 1). sCal was also significantly higher than in healthy controls, measured at $1737 \mathrm{ng} / \mathrm{mL}$.

Furthermore, the serum calprotectin also correlates with some clinical (tender joint counts [TJC] and CHAQ) and biological (ESR and C-reactive protein [CRP]) markers of disease activity. There is an even greater correlation with ESR $(r=0.79, p<0.001)$ than with CRP $(r=0.45, p<0.05)$, and sCal correlates to a lesser extent with JADAS10-CRP score $(r=0.2, p<0.05)$. However, the evolution of sCal correlated well with the evolution of JADAS10-CRP over time $(r=0.8, p<0.05)$. Moreover, the evolution of DAS28 score correlated strongly with the evolution of $s$ al over the same period of time $(r=1, p<0.05)$, but not with the CRP.

\section{Levels of serum calprotectin according to clinical subgroups}

Systemic arthritis differs significantly from polyarthritis, enthesitis-related arthritis and oligoarthritis with regard to levels of sCal and CRP (Fig. 2). When all forms of oligoarthritis (enthesitis-related arthritis [ERA], 
persistent and extended) are grouped and considered as a whole, their levels of sCal $(7515 \mathrm{ng} / \mathrm{mL})$ also differ significantly from polyarthritis $(14714 \mathrm{ng} / \mathrm{mL})$ and systemic arthritis $(26976 \mathrm{ng} / \mathrm{mL})$. Enthesitisrelated arthritis was associated with the lowest levels of sCal and CRP. All subgroups included patients with both active and inactive disease, on or off treatment, and did not differ from each other according to these conditions.

\section{Levels of serum calprotectin according to the response to treatment}

Among the 35 patients with active disease at baseline and starting a new treatment, $68.6 \%$ will reach a state of minimal disease activity according to their JADAS score at 6 months (or 9 months if lack of follow-up data at 6 months). These patients did not differ from those with an active disease at 6 months with regard to any clinical or laboratory parameters at baseline, except for higher levels of sCal, whereas CRP did not allow similar discrimination (Table 1, Fig. 3A).

Table 1 - Clinical and biologic parameters among patients achieving minimal disease activity and patients with an active disease after 6 months 


\begin{tabular}{|c|c|c|c|}
\hline & $\begin{array}{l}\text { Minimal disease activity } \\
(n=24)\end{array}$ & $\begin{array}{l}\text { Active disease } \\
(n=11)\end{array}$ & p-value \\
\hline $\begin{array}{l}\text { Age at disease onset, years } \\
\text { median (range) }\end{array}$ & $8.5(1.1-15.8)$ & $12.6(2.8-16.7)$ & ns \\
\hline $\begin{array}{l}\text { Disease duration, years } \\
\text { median (range) }\end{array}$ & $2.5(0.2-15.1)$ & $3.3(0.1-8.9)$ & ns \\
\hline $\begin{array}{l}\text { Female sex } \\
\mathrm{n}(\%)\end{array}$ & $12(50.0)$ & $5(45.5)$ & ns \\
\hline $\begin{array}{l}\text { Categories of JIA } \\
\mathrm{n}(\%)\end{array}$ & & & ns \\
\hline Systemic & $3(12.5)$ & $1(9.1)$ & \\
\hline Oligoarthritis & $13(54.2)$ & $4(36.4)$ & \\
\hline Persistent & $9(37.5)$ & $3(27.3)$ & \\
\hline Extended & $4(16.7)$ & $1(9.1)$ & \\
\hline PA-RF+ & $1(4.2)$ & $1(9.1)$ & \\
\hline PA-RF- & $2(8.3)$ & $1(9.1)$ & \\
\hline Psoriatic arthritis & 0 & 0 & \\
\hline ERA & $5(20.8)$ & $4(36.4)$ & \\
\hline Undifferentiated & 0 & 0 & \\
\hline $\begin{array}{l}\text { ANA+ } \\
\mathrm{n}(\%)\end{array}$ & $7(29.2)$ & $1(9.1)$ & ns \\
\hline $\begin{array}{l}\text { Number of DMARDs used } \\
\text { mean (SEM) }\end{array}$ & $1.3(0.2)$ & $2.1(0.3)$ & ns \\
\hline $\begin{array}{l}\text { TJC } \\
\text { mean (SEM) }\end{array}$ & $1.7(0.5)$ & $1.4(0.5)$ & ns \\
\hline $\begin{array}{l}\text { SJC } \\
\text { mean (SEM) }\end{array}$ & $1.9(0.6)$ & $3.1(1.6)$ & ns \\
\hline $\begin{array}{l}\text { Physician VAS } \\
\text { mean (SEM) }\end{array}$ & $19.1(3.8)$ & $27.8(6.1)$ & ns \\
\hline Patient/parent VAS & $18.9(6.9)$ & $25.4(8.2)$ & ns \\
\hline
\end{tabular}




\begin{tabular}{|c|c|c|c|}
\hline $\begin{array}{l}\text { CHAQ } \\
\text { mean (SEM) }\end{array}$ & $0.3(0.1)$ & $0.4(0.2)$ & ns \\
\hline $\begin{array}{l}\text { CRP, mg/L } \\
\text { mean (SEM) }\end{array}$ & $10.9(3.5)$ & $11.5(3.4)$ & ns \\
\hline $\begin{array}{l}\text { ESR, mm/h } \\
\text { mean (SEM) }\end{array}$ & $21.5(9.3)$ & $36.5(8.7)$ & ns \\
\hline $\begin{array}{l}\text { DAS-28CRP } \\
\text { mean (SEM) }\end{array}$ & $2.5(0.3)$ & $2.7(0.4)$ & ns \\
\hline $\begin{array}{l}\text { JADAS10-CRP } \\
\text { mean (SEM) }\end{array}$ & $6.2(1.3)$ & $8.6(2.2)$ & ns \\
\hline $\begin{array}{l}\text { sCal, ng/mL } \\
\text { mean (SEM) }\end{array}$ & $12138(2133)$ & 5165 (1255) & $*(0.03)$ \\
\hline
\end{tabular}

JIA, juvenile idiopathic arthritis; PA, polyarthritis; RF, rheumatoid factor; ERA, enthesitis-related arthritis; ANA, antinuclear antibody; SEM, standard error of the mean; TJC, tender joint count; SJC, swollen joint count; VAS, disease evaluation on a visual analogue scale; CRP, C-reactive protein; ESR, erythrocyte sedimentation rate; sCal, serum calprotectin. Results are given as number +/- percentages, median +/range, or mean $+/$ - SEM. Statistical significance ( ${ }^{*}<<0.05$, ns: not significant) was assessed by MannWhitney test.

With a threshold fixed at $9095 \mathrm{ng} / \mathrm{mL}$, the ROC curves obtained a sensitivity of $91 \%$ and a specificity of $46 \%$, with a likelihood ratio of 1.68 and an area under the curve (AUC) of 0.73 (Fig. 3B).

\section{Levels of serum calprotectin according to the risk of flares}

Within the 45 patients in remission at baseline, $8.9 \%$ will experience a flare in the following 3 to 9 months. They had significantly higher levels of $\mathrm{sCal}$ at baseline than patients who remained in prolonged remission under stable treatment (Table 2, Fig. 4A). No difference in CRP levels was seen between the groups.

Table 2 - Serum calprotectin and C-reactive protein levels according to risk of flares among patients in remission 


\begin{tabular}{|c|c|c|c|}
\hline & $\begin{array}{l}\text { Flare within } 3 \text { to } 9 \text { months } \\
(n=4)\end{array}$ & $\begin{array}{l}\text { No flare within } 3 \text { to } 9 \text { months } \\
(n=41)\end{array}$ & p-value \\
\hline $\begin{array}{l}\text { sCal, ng/mL } \\
\text { mean (SEM) }\end{array}$ & $26073(5295)$ & 7066 (1126) & $\star * \star(0.001)$ \\
\hline $\begin{array}{l}\text { CRP, mg/L } \\
\text { mean (SEM) }\end{array}$ & $0.6(0.5)$ & $1.2(0.2)$ & ns \\
\hline
\end{tabular}

sCal, serum calprotectin; CRP, C-reactive protein. Results are given as mean +/- SEM. Statistical significance ( ${ }^{\star \star \star} p<0.001, \mathrm{~ns}$ : not significant) was assessed by Mann-Whitney test.

The analysis of ROC curves identified a threshold fixed at $10285 \mathrm{ng} / \mathrm{mL}$ associated with a sensitivity of $100 \%$, a specificity of $78 \%$ and a likelihood ratio of 4.56 (Fig. 4B). The AUC was in this case of 0.95 .

\section{Discussion}

The levels of sCal were significantly higher in JIA patients than in healthy controls, being further increased with disease activity, as previously found by other teams.[14,16,30] Serum calprotectin correlates with TJC and may also be a reflection of disease severity (CHAQ), as previously reported by some authors.[14,30] We confirm its correlation with inflammatory markers (CRP and ESR) [16,30] but discover a large variability of sCal for normal CRP values. Moreover, unlike CRP, sCal is strongly correlated with the evolution of disease activity according to JADAS10 and DAS28. All these data are consistent with the results obtained in other inflammatory diseases, $[5,6,8,9,12,13]$ which underline the interest of sCal as a marker of disease activity and therefore of disease severity. In particular, a recent study showed that high plasma levels of calprotectin could be a robust biomarker for severe forms of COVID-19.[13]

Our data show that sCal has the same ability as CRP to differentiate between oligoarthritis, polyarthritis and systemic forms, thus confirming the results described in systemic forms by Frosch et al.[15] Enthesitis-related arthritis forms also tend to have lower levels of sCal compared to other forms, and polyarthritis forms tend to have intermediate levels of sCal ranging between systemic and oligoarthritis forms. This highlights the potentially crucial role of sCal in aiding the diagnosis of JIA. Although interpretation of these results may be limited by the number of patients, it appears that the patients with ERA in our cohort predominantly had a combination of arthritis and enthesitis, or isolated enthesitis. Specifically, 8 of these 11 patients had arthritis ( 6 with oligoarticular and 2 with polyarticular forms), including 4 with associated enthesitis. Two patients had isolated enthesitis. Moreover, 4 out of the 11 patients had sacroiliitis, including 2 isolated forms.

A major take-away of this study is the confirmation of sCal as a predictive marker of good response to treatment (all types of treatment combined), as also shown in 2 recent cohort studies with patients 
treated with methotrexate or TNF-inhibitors.[20,31] It is important to note that the cut-off obtained from the ROC curve does not provide a perfect prediction, so the treatment decision cannot be based solely on sCal levels and must take into account other clinical factors. In addition, current medical practice suggests an increasingly personalized medicine. Thereby, more and more studies, such as ours, are investigating molecules of interest that can guide the therapeutic process, often derived from promising studies in the broad field of rheumatoid arthritis[32-34] that could inspire further future studies in JIA. Furthermore, it has recently been shown that $\mathrm{SCal}$ can be easily and rapidly detected in blood using a lateral flow immunoassay (LFIA) based technology, which may provide a useful point-of-care testing.[16]

The second key point of this study underscores the utility of sCal as a highly significant predictive marker of relapse when measured in patients in remission, as outlined by other teams.[17-20,30,35] The very high sCal values found in patients with a subsequent flare may be striking, but they were not skewed by possible systemic forms; indeed, these patients had persistent-oligoarthritis or seronegative polyarthritis forms of JIA. Serum calprotectin could therefore be a marker of residual disease activity, even in the absence of clinical or biological signs of persistent inflammation. It could thus play a role in patient follow-up, helping to identify patients in remission under treatment who are likely to remain in prolonged remission and therefore discuss discontinuation or tapering of treatment without risk of future relapses. However, there were only 4 patients with a subsequent flare in our study; therefore, these results should be further validated before being used in clinical practice. More recently, Hinze et al did not find similar results when following patients with a polyarticular course treated with TNF-inhibitors, but this prospective study evaluated the predictive value of sCal levels measured at baseline in patients with clinically inactive disease on anti-TNF therapy and followed-up for a period of 6 months, and then at the time of long-term treatment discontinuation.[36] In contrast, our study evaluated the use of sCal to predict the risk of flare-ups under treatment maintained during the 9-months of follow-up. The results are therefore not comparable and the duration of follow-up on stable therapy is not identical. Our study therefore highlights a group of patients at risk of relapse who may benefit from more frequent follow-up for a longer period, even if they are in an apparently reassuring state of remission. Another recent study could not find a relationship between $\mathrm{sCal}$ and prediction of treatment response and flare; this study excluded systemic forms (which may be more inflammatory and aggressive, and thus perhaps more related to sCal variations) and included two very different cohorts.[37] Overall, this underlines the fact that JIA is a very heterogeneous disease with few comparable studies.

A prospective non-randomized clinical trial investigating stratified biomarker-based treatment approaches in patients with polyarticular course has just completed recruitment and results are expected in December 2020 (ISRCTN 69963079). In light of recent results,[36,37] it might also be interesting to study sCal in oligoarticular and systemic forms to evaluate its efficacy as a prognostic marker in other specific subgroups of patients (the results from Hinze et al tend to show that dosage of sCal under stable treatment might be discriminating in extended oligoarthritis and seropositive polyarthritis, but not in seronegative polyarthritis). It may also be of interest to assess sCal levels in patients who taper, but do not completely discontinue, their treatment. 
A limitation of our study is our control cohort consisting of young adults, instead of children comparable to our patients. However, serum calprotectin levels measured in previous studies did not differ significantly with regard to age or sex distribution in the control cohort.[17,38] It should also be noted that patients under anti-TNF therapy could theoretically exhibit modified sCal secretion due to decreased TNF levels following treatment and thus potential downregulation of the $S 100$ proteins inflammatory pathway. [39] In our study, $18 \%$ of patients were on anti-TNF therapy, whereas the vast majority ( $75 \%$ of patients) was on methotrexate treatment (which would affect the $\mathrm{S} 100$ proteins pathway less). Another limitation is a potential selection bias regarding the patients included from specialized centers, potentially having more severe disease, and therefore requiring more treatment. The heterogeneity of the JIA spectrum also leads to a more strenuous analysis in subgroups. Finally, partial retrospective data collection may also misrepresent some results.

\section{Conclusions}

This study confirms the interest of sCal as a diagnostic tool and as a marker of activity. In particular, it could represent a predictive marker of response to treatment, or persistence of inactive disease, that could be used routinely. This protein is indeed relatively stable and easily measurable in serum.

\section{Key Messages}

\section{What is already known about this subject?}

- Serum calprotectin was shown to be elevated in patients with juvenile idiopathic arthritis with active disease, particularly in the systemic form.

- Serum calprotectin has shown promising results as a biomarker by predicting disease relapse after stopping NSAIDs, methotrexate or etanercept treatment.

\section{What does this study add?}

- This study confirms the interest of serum calprotectin as a potential marker of response to treatment or risk of flares.

- It also highlights its role as a useful diagnostic tool and marker of disease activity, with a greater specificity than with CRP.

\section{How might this impact on clinical practice or future developments?}

- Since calprotectin is not yet routinely used, the more studies that confirm its usefulness, the more likely it will be implemented in our clinical practice and help us better manage our patients. 


\section{Declarations}

\section{Ethics}

This study complies with the Declaration of Helsinki and was approved by the ethics comities of each hospital involved. Informed consent has been obtained from each patient and parents.

\section{Consent for publication}

Not applicable.

\section{Availability of data and materials}

All data generated or analysed during this study are included in this published article and its supplementary information files.

\section{Competing interest}

None declared.

\section{Funding}

This work was supported by the Radio-Télévision belge de la Communauté française (RTBF) via the CAP48 program. The funding body had no role in the design of the study, or in the collection, analysis, and interpretation of data or the in writing the manuscript.

\section{Authors' contributions}

CL performed the ELISA tests, analyzed and interpreted all data, and wrote the manuscript. All authors made substantial contributions to the acquisition of data. All authors read and approved the final manuscript.

\section{Acknowledgements}

Julie Smet ${ }^{1}$ and the investigators of the CAP48 cohort: Jean-Pierre Brasseur ${ }^{2}$, Benoît Brasseur ${ }^{3}$ and David Tuerlinckx ${ }^{3}$.

${ }^{1}$ Laboratory of Immunobiology, Hôpital Erasme, Brussels, Belgium

${ }^{2}$ Department of Rheumatology, Hôpital Mont-Godinne, Mont-Godinne, Belgium

${ }^{3}$ Department of Pediatrics, Hôpital Mont-Godinne, Mont-Godinne, Belgium

\section{References}


1 Petty RE, Southwood TR, Manners P, et al. International League of Associations for Rheumatology classification of juvenile idiopathic arthritis: second revision, Edmonton, 2001. J Rheumatol 2004;31:390-2.

2 Ravelli A, Martini A. Juvenile idiopathic arthritis. Lancet Lond Eng/ 2007;369:767-78. doi:10.1016/S0140-6736(07)60363-8

3 Prakken B, Albani S, Martini A. Juvenile idiopathic arthritis. Lancet Lond Eng/2011;377:2138-49. doi:10.1016/S0140-6736(11)60244-4

4 Foell D, Wittkowski H, Vogl T, et al. S100 proteins expressed in phagocytes: a novel group of damage-associated molecular pattern molecules. J Leukoc Bio/ 2007;81:28-37. doi:10.1189/jlb.0306170

5 Meuwis M-A, Vernier-Massouille G, Grimaud JC, et al. Serum calprotectin as a biomarker for Crohn's disease. J Crohns Colitis 2013;7:e678-683. doi:10.1016/j.crohns.2013.06.008

6 Reid PA, McAllister DA, Boyd AC, et al. Measurement of serum calprotectin in stable patients predicts exacerbation and lung function decline in cystic fibrosis. Am J Respir Crit Care Med 2015;191:233-6. doi:10.1164/rccm.201407-1365LE

7 Bartáková E, Štefan M, Stráníková A, et al. Calprotectin and calgranulin C serum levels in bacterial sepsis. Diagn Microbiol Infect Dis 2019;93:219-26. doi:10.1016/j.diagmicrobio.2018.10.006

8 Jarlborg M, Courvoisier DS, Lamacchia C, et al. Serum calprotectin: a promising biomarker in rheumatoid arthritis and axial spondyloarthritis. Arthritis Res Ther 2020;22:105. doi:10.1186/s13075-02002190-3

9 Inciarte-Mundo J, Ramirez J, Hernández MV, et al. Calprotectin strongly and independently predicts relapse in rheumatoid arthritis and polyarticular psoriatic arthritis patients treated with tumor necrosis factor inhibitors: a 1-year prospective cohort study. Arthritis Res Ther 2018;20:275. doi:10.1186/s13075018-1764-z

10 Tweehuysen L, den Broeder N, van Herwaarden N, et al. Predictive value of serum calprotectin (S100A8/A9) for clinical response after starting or tapering anti-TNF treatment in patients with rheumatoid arthritis. RMD Open 2018;4:e000654. doi:10.1136/rmdopen-2018-000654

11 Verstappen M, van Mulligen E, de Jong PHP, et al. DMARD-free remission as novel treatment target in rheumatoid arthritis: A systematic literature review of achievability and sustainability. RMD Open 2020;6. doi:10.1136/rmdopen-2020-001220

12 Tydén H, Lood C, Gullstrand B, et al. Pro-inflammatory S100 proteins are associated with glomerulonephritis and anti-dsDNA antibodies in systemic lupus erythematosus. Lupus 2017;26:139-49. doi:10.1177/0961203316655208 
13 Silvin A, Chapuis N, Dunsmore G, et al. Elevated Calprotectin and Abnormal Myeloid Cell Subsets Discriminate Severe from Mild COVID-19. Cell 2020;182:1401-1418.e18. doi:10.1016/j.cell.2020.08.002

14 Frosch M, Strey A, Vogl T, et al. Myeloid-related proteins 8 and 14 are specifically secreted during interaction of phagocytes and activated endothelium and are useful markers for monitoring disease activity in pauciarticular-onset juvenile rheumatoid arthritis. Arthritis Rheum 2000;43:628-37. doi:10.1002/1529-0131(200003)43:3<628::AID-ANR20>3.0.CO;2-X

15 Frosch M, Vogl T, Seeliger S, et al. Expression of myeloid-related proteins 8 and 14 in systemiconset juvenile rheumatoid arthritis. Arthritis Rheum 2003;48:2622-6. doi:10.1002/art.11177

16 Foell D, Park C, Ziegler L, et al. Successful Validation of a Rapid Point-of-care Test for Serum Calprotectin (MRP8/14) as Biomarker in Juvenile Idiopathic Arthritis [abstract]. Arthritis Rheumatol Hoboken NJ 2020;72.https://acrabstracts.org/abstract/successful-validation-of-a-rapid-point-of-care-testfor-serum-calprotectin-mrp8-14-as-biomarker-in-juvenile-idiopathic-arthritis/ (accessed 8 Dec 2020).

17 Rothmund F, Gerss J, Ruperto N, et al. Validation of relapse risk biomarkers for routine use in patients with juvenile idiopathic arthritis. Arthritis Care Res 2014;66:949-55. doi:10.1002/acr.22248

18 Foell D, Frosch M, Schulze zur Wiesch A, et al. Methotrexate treatment in juvenile idiopathic arthritis: when is the right time to stop? Ann Rheum Dis 2004;63:206-8. doi:10.1136/ard.2003.005686

19 Gerss J, Roth J, Holzinger D, et al. Phagocyte-specific S100 proteins and high-sensitivity C reactive protein as biomarkers for a risk-adapted treatment to maintain remission in juvenile idiopathic arthritis: a comparative study. Ann Rheum Dis 2012;71:1991-7. doi:10.1136/annrheumdis-2012-201329

20 Anink J, Van Suijlekom-Smit LWA, Otten MH, et al. MRP8/14 serum levels as a predictor of response to starting and stopping anti-TNF treatment in juvenile idiopathic arthritis. Arthritis Res Ther 2015;17:200. doi:10.1186/s13075-015-0723-1

21 Wells G, Becker J-C, Teng J, et al. Validation of the 28-joint Disease Activity Score (DAS28) and European League Against Rheumatism response criteria based on C-reactive protein against disease progression in patients with rheumatoid arthritis, and comparison with the DAS28 based on erythrocyte sedimentation rate. Ann Rheum Dis 2009;68:954-60. doi:10.1136/ard.2007.084459

22 Ringold S, Bittner R, Neogi T, et al. Performance of rheumatoid arthritis disease activity measures and juvenile arthritis disease activity scores in polyarticular-course juvenile idiopathic arthritis: Analysis of their ability to classify the American College of Rheumatology pediatric measures of response and the preliminary criteria for flare and inactive disease. Arthritis Care Res 2010;62:1095-102. doi:10.1002/acr.20205

23 Consolaro A, Ruperto N, Bazso A, et al. Development and validation of a composite disease activity score for juvenile idiopathic arthritis. Arthritis Rheum 2009;61:658-66. doi:10.1002/art.24516 
24 Backström M, Tynjälä P, Ylijoki H, et al. Finding specific 10-joint Juvenile Arthritis Disease Activity Score (JADAS10) and clinical JADAS10 cut-off values for disease activity levels in non-systemic juvenile idiopathic arthritis: a Finnish multicentre study. Rheumatol Oxf Eng/ 2016;55:615-23.

doi:10.1093/rheumatology/kev353

25 Consolaro A, Ruperto N, Bracciolini G, et al. Defining criteria for high disease activity in juvenile idiopathic arthritis based on the juvenile arthritis disease activity score. Ann Rheum Dis 2014;73:1380-3. doi:10.1136/annrheumdis-2013-204186

26 Wallace CA, Giannini EH, Huang B, et al. American College of Rheumatology provisional criteria for defining clinical inactive disease in select categories of juvenile idiopathic arthritis. Arthritis Care Res 2011;63:929-36. doi:10.1002/acr.20497

27 Consolaro A, Bracciolini G, Ruperto N, et al. Remission, minimal disease activity, and acceptable symptom state in juvenile idiopathic arthritis: defining criteria based on the juvenile arthritis disease activity score. Arthritis Rheum 2012;64:2366-74. doi:10.1002/art.34373

28 Brunner HI, Lovell DJ, Finck BK, et al. Preliminary definition of disease flare in juvenile rheumatoid arthritis. J Rheumatol 2002;29:1058-64.

29 Dempster $\mathrm{H}$, Porepa $\mathrm{M}$, Young $\mathrm{N}$, et al. The clinical meaning of functional outcome scores in children with juvenile arthritis. Arthritis Rheum 2001;44:1768-74. doi:10.1002/1529-

0131(200108)44:8<1768::AID-ART312>3.0.C0;2-Q

30 Holzinger D, Frosch M, Kastrup A, et al. The Toll-like receptor 4 agonist MRP8/14 protein complex is a sensitive indicator for disease activity and predicts relapses in systemic-onset juvenile idiopathic arthritis. Ann Rheum Dis 2012;71:974-80. doi:10.1136/annrheumdis-2011-200598

31 Moncrieffe $\mathrm{H}$, Ursu S, Holzinger D, et al. A subgroup of juvenile idiopathic arthritis patients who respond well to methotrexate are identified by the serum biomarker MRP8/14 protein. Rheumatol Oxf Eng/2013;52:1467-76. doi:10.1093/rheumatology/ket152

32 Bach M, Moon J, Moore R, et al. A Neutrophil Activation Biomarker Panel in Prognosis and Monitoring of Patients With Rheumatoid Arthritis. Arthritis Rheumatol Hoboken NJ 2020;72:47-56. doi:10.1002/art.41062

33 Hu F, Jiang X, Guo C, et al. Scavenger receptor-A is a biomarker and effector of rheumatoid arthritis: A large-scale multicenter study. Nat Commun 2020;11:1911. doi:10.1038/s41467-020-15700-3

34 Ciregia F, Baiwir D, Cobraiville G, et al. Glycosylation deficiency of lipopolysaccharide-binding protein and corticosteroid-binding globulin associated with activity and response to treatment for rheumatoid arthritis. J Trans/ Med 2020;18:8. doi:10.1186/s12967-019-02188-9 
35 Foell D, Wulffraat N, Wedderburn LR, et al. Methotrexate withdrawal at 6 vs 12 months in juvenile idiopathic arthritis in remission: a randomized clinical trial. JAMA 2010;303:1266-73.

doi:10.1001/jama.2010.375

36 Hinze CH, Foell D, Johnson AL, et al. Serum S100A8/A9 and S100A12 Levels in Children With Polyarticular Forms of Juvenile Idiopathic Arthritis: Relationship to Maintenance of Clinically Inactive Disease During Anti-Tumor Necrosis Factor Therapy and Occurrence of Disease Flare After Discontinuation of Therapy. Arthritis Rheumatol Hoboken NJ 2019;71:451-9. doi:10.1002/art.40727

37 Barendregt AM, Veldkamp SR, Hissink Muller PCE, et al. MRP8/14 and neutrophil elastase for predicting treatment response and occurrence of flare in patients with juvenile idiopathic arthritis. Rheumatol Oxf Eng/2020;59:2392-401. doi:10.1093/rheumatology/kez590

38 Frosch M, Ahlmann M, Vogl T, et al. The myeloid-related proteins 8 and 14 complex, a novel ligand of toll-like receptor 4 , and interleukin-1 beta form a positive feedback mechanism in systemic-onset juvenile idiopathic arthritis. Arthritis Rheum 2009;60:883-91. doi:10.1002/art.24349

39 Xu K, Geczy CL. IFN-gamma and TNF regulate macrophage expression of the chemotactic S100 protein S100A8. J Immunol Baltim Md 1950 2000;164:4916-23. doi:10.4049/jimmunol.164.9.4916

\section{Figures}




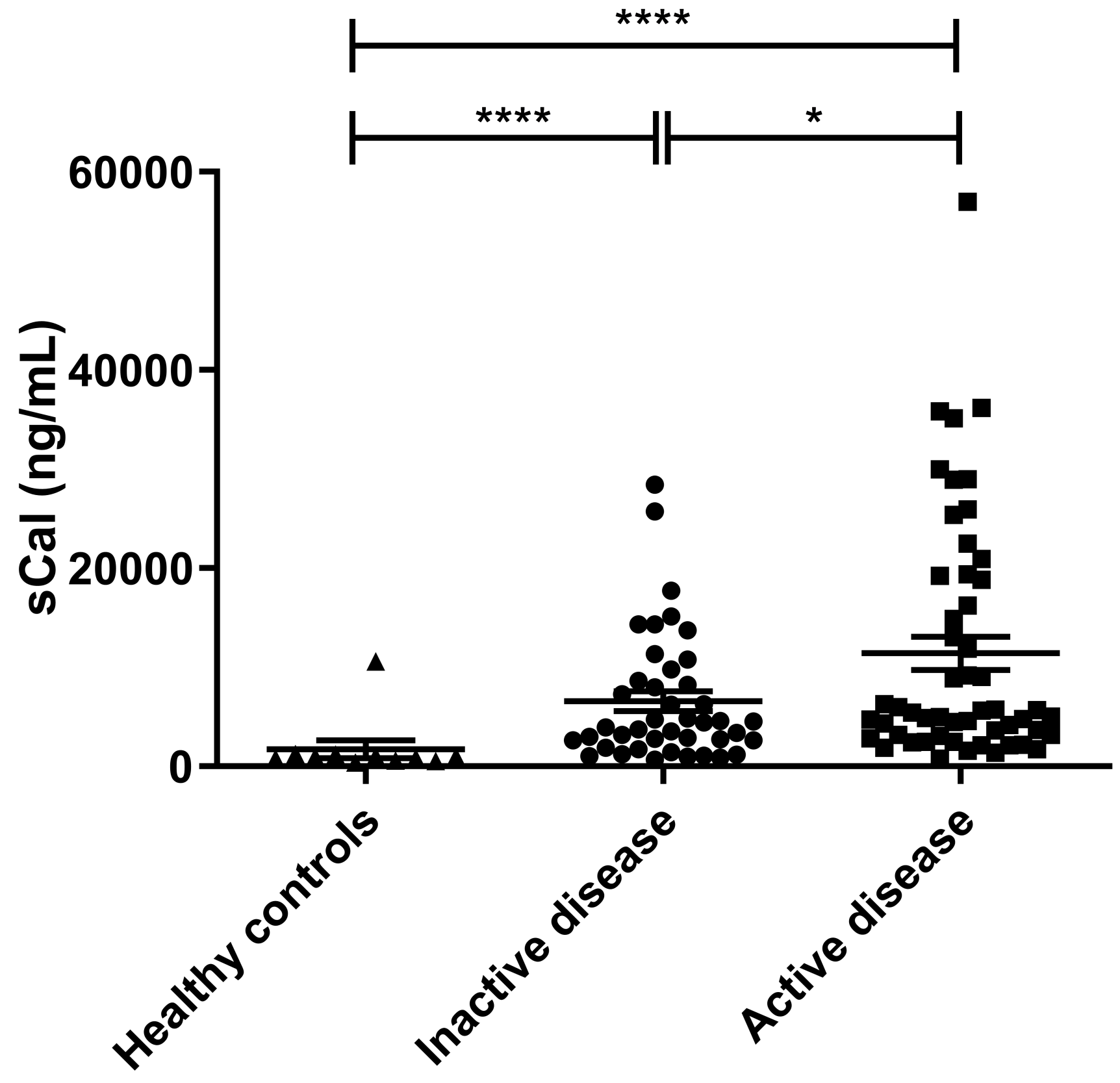

Figure 1

Levels of serum calprotectin according to disease activity. sCal, serum calprotectin. Results are given as mean $+/$ - SEM. Statistical significance $\left({ }^{\star} p<0.05,{ }^{\star \star \star \star} p<0.0001\right)$ was assessed by Mann-Whitney test. 
A

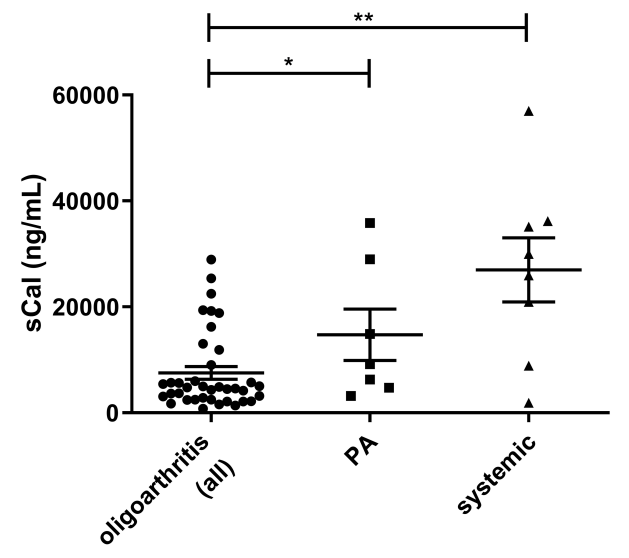

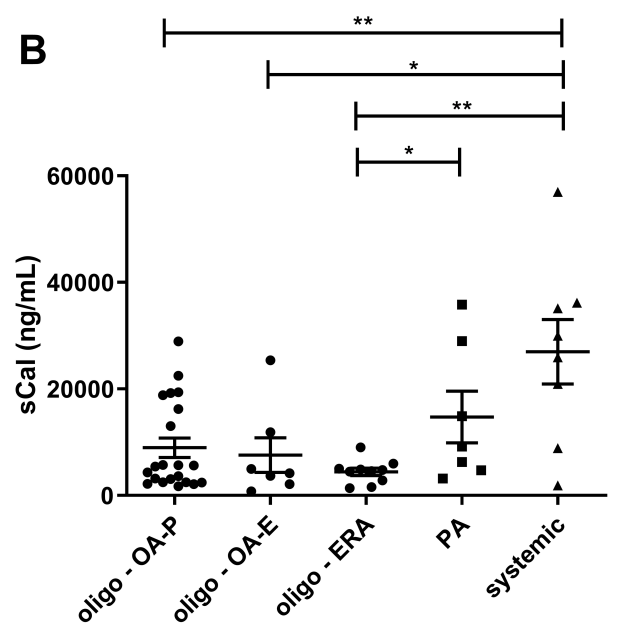

\section{Figure 2}

Levels of serum calprotectin or C-reactive protein according to clinical subgroups. (A-B) Levels of serum calprotectin according to clinical subgroups, with all forms of oligoarthritis grouped (A) or separated according to their categories (B). (C) Levels of C-reactive protein according to clinical subgroups. sCal, serum calprotectin; PA, polyarthritis; OA-P, persistent form of oligoarthritis; OA-E, extended form of oligoarthritis; ERA, enthesitis-related arthritis; CRP, C-reactive protein. Results are given as mean +/- SEM $(A-C)$. Statistical significance $\left({ }^{*} p<0.05,{ }^{* \star} p<0.01,{ }^{* * \star *} p<0.0001\right)$ was assessed by Mann-Whitney test.

A

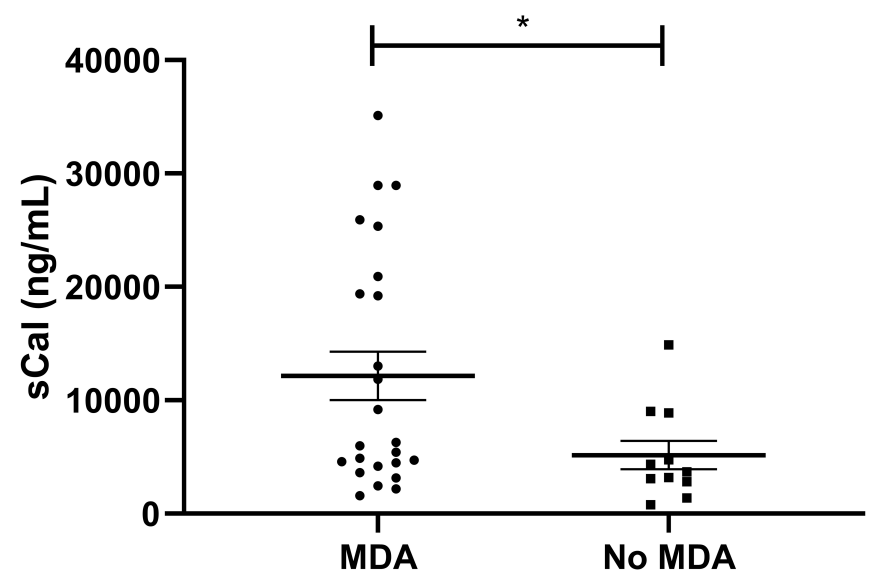

B

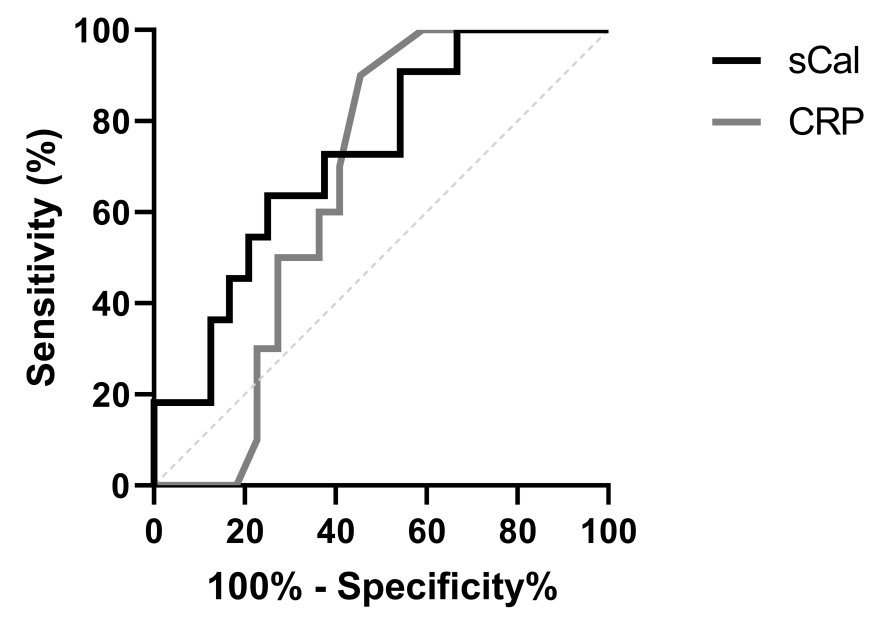

Figure 3

Levels of serum calprotectin according to the response to treatment. (A) Levels of serum calprotectin in patients with an active disease and starting a new treatment, according to their ability to reach minimal disease activity. (B) ROC curves of response to treatment according to serum calprotectin or C-reactive 
protein. MDA, minimal disease activity; sCal, serum calprotectin; CRP, C-reactive protein. Results are given as mean $+/$ - SEM (A). Statistical significance $\left({ }^{*} p<0.05\right)$ was assessed by Mann-Whitney test $(A)$.

A

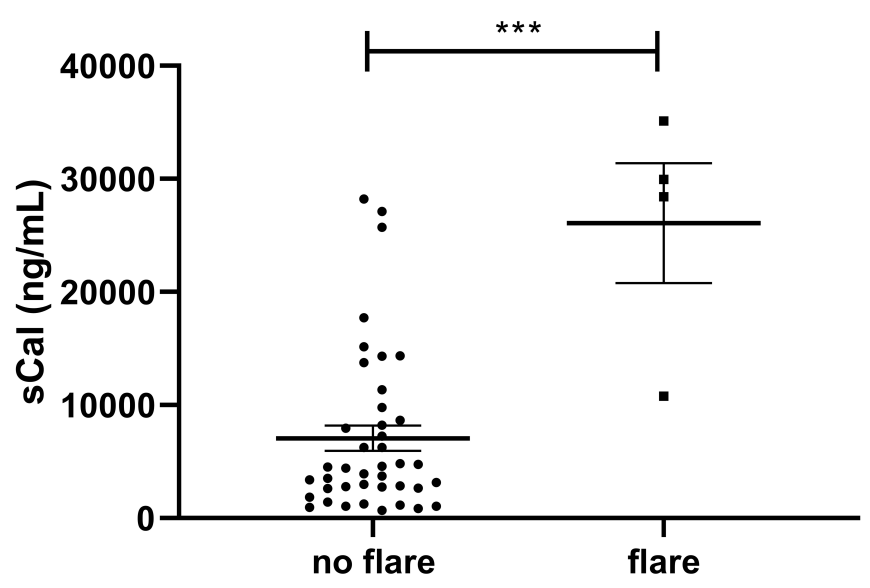

B

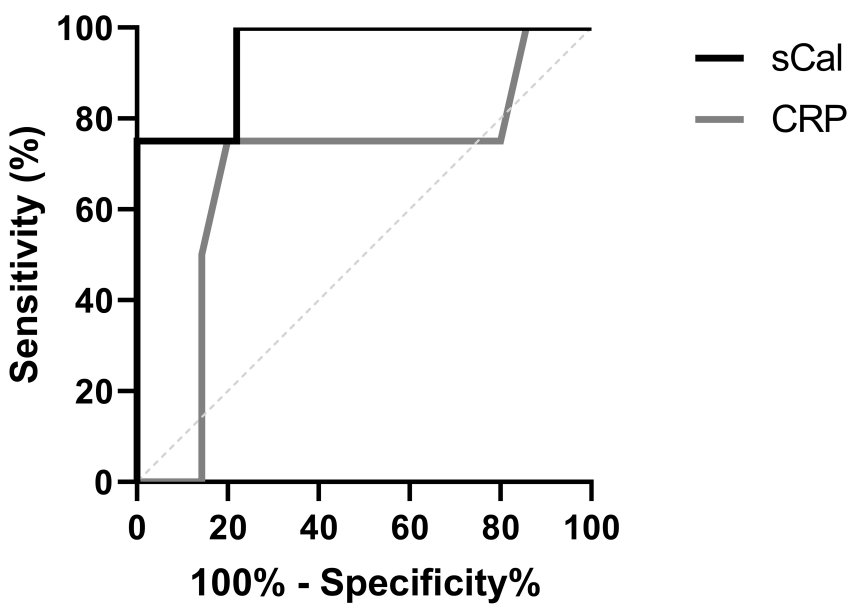

Figure 4

Levels of serum calprotectin according to the risk of flares. (A) Levels of serum calprotectin according to the risk of flare among patients in remission. (B) ROC curves of risk of flares according to serum calprotectin or C-reactive protein. sCal, serum calprotectin; CRP, C-reactive protein. Results are given as mean $+/$ - SEM $(A)$. Statistical significance $\left({ }^{* \star *} p<0.001\right)$ was assessed by Mann-Whitney test $(A)$.

\section{Supplementary Files}

This is a list of supplementary files associated with this preprint. Click to download.

- Supplementaryfile1.docx 